\title{
Budget Forgets That Tertiary Education is the Foundation of the Future ${ }^{1}$
}

New Zealand Journal of Teachers' Work, Volume 15, Issue 1, 3-4, 2018

\section{TERTIARY EDUCATION UNION}

Prime Minister Jacinda Ardern's aspiration that this Budget provides a foundation for the future has been dealt a severe blow by the failure to invest further in tertiary education.

Aspects of the Budget welcomed by the Tertiary Education Union include the commitment to build more houses, extend low cost GP visits, invest in rebuilding the health system, and ensure we have enough teachers to inspire our kids. However, the TEU has been left wondering how it is possible to meet these commitments without a fully funded, accessible tertiary education sector.

People working in the tertiary sector are the foundation of the future. They are the people that train the future builders we need to build the new homes the government is committed to, the GPs that will now be made more accessible, and the nurses, midwives, teachers and social workers who will also, rightly, be supported by this Budget. However, the reality is that these commitments have been put at risk because of the Finance Minister's failure to address the $\$ 3.7$ billion funding hole the tertiary education sector faces - a hole that will be made even worse through the Budget's failure even to offer an inflation-linked funding increase. The TEU is calling on the Minister for Education to urgently come forward with a plan to work with the sector to change the tertiary education funding model over the next 12 months, so that next year's Budget does provide a genuine foundation for the future.

Sandra Grey, national president of the Tertiary Education Union, said:

The Prime Minister has spoken about this being a Budget for the next generation, and the tertiary education sector is absolutely critical to meeting her commitment. Houses cannot be built without trained builders, people cannot visit a GP without trained doctors, kids cannot be taught without trained teachers, and children cannot be supported without trained social workers. Tertiary education is what connects these vital professions to the commitments in this Budget, and the better New Zealand the Prime Minister is so passionate about. Yet the sector seems to have been forgotten.

\footnotetext{
${ }^{1}$ Reprinted with permission. Original at http://teu.ac.nz/2018/05/budget-failed-foundation/
} 
Labour is at risk of going into the next election having fulfilled its commitment to provide one year of free tertiary education, which we welcome, but little else that will ensure these students actually have places to study in their local communities. Labour needs something else to point to - so it can say to the New Zealand public that it has brought about genuine change and in doing so has ensured that we do have the doctors, nurses, builders, social workers and teachers we desperately need. The Minister needs to work with us to make that happen.

The opinions expressed are those of the paper author(s) and not the New Zealand Journal of Teachers' Work. Copyright is held by individual authors but offprints in the published format only may be distributed freely by individuals provided that the source is fully acknowledged. [ISSN-1176-6662] 